\title{
Utopian Theatre and Subjectivity Reconstruction—Rethinking on the Artistic Spirit of Minjian Theatre ${ }^{1}$
}

\begin{abstract}
YANG Zi
Shanghai Arts Research Institute, Shanghai, China

Minjian has become an important concept in recent scholarly research. It is widely used by scholars to indicate specific social and cultural spaces existing beyond the control of state power, therefore, minjian social-cultural spaces are more often than not marginal and peripheral. In the field of performing arts, minjian theatre refers to performances produced by private theatre companies as opposed to state-run groups. These private companies or grass-root groups, without the interference of the government, produce artistic expressions that reflect current social reality to a certain extent. For a long time, the study of minjian theatre has been framed as forms of resistance against the ideology propagated by state-run theatres. Based on this paradigm, this paper, through the case analysis of Shanghai minjian theatre companies, attempts to illuminate the production mechanism and developmental process of minjian theatres. In so dong, this paper will explore the aesthetic and social-political values of minjian theatres.
\end{abstract}

Keywords: Minjian Theatre Theatrical Practice Utopian Theatre

Theatre is integrated with the times, the society and the culture. It cannot be isolated or separated from a specific culture and the society in which it exists, so its development and transition can be a reflection of the social and cultural transformation of contemporary Chinese society and a miniature of current urban society. Therefore, the relationship between theatre and transformative society have been hotly discussed in the theatrical research in recent years.

"Minjian" (literally between folks) has become an important concept in recent scholarly research. ${ }^{2}$ It is widely used by scholars to indicate specific social and cultural spaces existing beyond the control of state power, therefore, minjian social-cultural spaces are more often than not marginal and peripheral. In the field of performing arts, when scholars use minjian theatre as a term, they talk about performances produced by private theatre companies as opposed to state-run groups. These private companies or grass-root groups, without the interference of the government, produce artistic expressions that reflect current social reality to a certain extent. For a long time, the study of minjian theatre has been framed as forms of resistance against the ideology propagated by state-run theatres. Based on this paradigm, this paper, through the case analysis of

\footnotetext{
${ }^{1}$ Acknowledgements: This paper was funded by the Major Projects of National Social Science Fund of China (15ZDB023).

YANG Zi is an Associate Professor at Shanghai Arts Research Institute. Her research interests include urban studies, theater, film and visual studies and cultural industry studies.

2 The concept of "Minjian" was first proposed by Chen Sihe in the 1990s. He made a systematic exposition in the two articles Floating in Minjianand Reduction of Minjian and explored the existence, value and significance of minjian with the development of literary history from 1937 onwards. It caused widespread attention in academia with its reinterpretation of the literature history, intellectual position and spiritual reconstruction and other major issues.
} 
Shanghai minjian theatre companies, attempts to illuminate the production mechanism and developmental process of minjian theatres. In so dong, this paper will explore the aesthetic and social-political values of minjian theatres.

The development of Shanghai minjian theatre companies is highly related to the opening of Downstream Garage, a non-profit theatre. Due to the strict management on performing qualifications from domestic cultural authorities, troupes cannot get performance license easily. While at the same time, the lack of rehearsal venues stalled the development of minjian theatre groups. It is arena but not money that the troupes need most. In 2005, the theatres in Shanghai became increasingly intimate with commercial interest, and white-collar dramas were especially popular. A non-profit theatre named Downstream Garage, located in an abandoned vintage warehouse on Longcao road, was founded by Wang Jingguo ${ }^{3}$, the former stage designer of Shanghai Youth Drama Troupe. The theatre provided free venue for Shanghai minjian theatre groups and artists to support the original experimental works and to set up a platform for drama lovers in Shanghai. Downstream Garage is free of charge and do not involve in any profitable projects. Daily operational expenses are supported by private business entities owned by Wang Jingguo. This non-commercial theatrical operation mode is more than a direct resistance to the capitallogic which dominates the current theatrical production and creates a precedent for anti-business mode in Shanghai. According to incomplete statistics, with the help of Downstream Garage, not only the number of troupes increased but the mechanism and style of such troupes also grew and improved, the non-vocational characteristics,in particular, became more prominent among the troupes. Minjian theatre groups such as Grass Stage, Zu He Niao, Uncertainty Theatre, Linc2 Theatre Company, 802 Drama Studio and Nine-dimensional Space are all founded in Shanghai, whose members are non-professional actors, who don't make a living by performing and advocate original, independent and freestyle theatrical productions.

Shanghai minjian theatre troupes are diversified and their main theatrical productions and stage styles depend on the core members of the troupes. Some influential theatrical troupes such as "Uncertainty Theatre", Grass Stage and Linc2 theatre Company are developed with the help of Downstream Garage. Investigation of theirtheatrical practice can be helpful to understand the artistic production mechanism and the development of Shanghai local minjian theatre troupes as well as specific expressions of social individuals in theatres, furthermore, we can take a glimpse at the spiritual essence of the minjian experimental theatres and a real image of the urban society.

\section{Anti-grammar Performance Theatre: Uncertainty Theatre}

In November 2004, an experimental performance group composed of poets, visual artists, university students and some theatrical professionals was formed and named after Uncertainty Theatre. The name originates from "the Uncertainty Principal" theory, which means that people cannot observe the original appearance of an object unbiasedly. As one of the founders of Uncertainty Theatre, Gao Xiaoqin, the poet of

\footnotetext{
${ }^{3}$ WANG Jingguo graduated from the department of fine arts of Shanghai Theater Academy in 1982, he worked as a stage designer in Shanghai Youth Drama Troupe, and created and presided over quite a number of works and projects in the field of Shanghai modern fine arts and drama. In 1991, he was listed in the 11th edition of the WHO's WHO compiled by Cambridge. In the same year, he accepted the invitation from U.S. RAGDALE Art Foundation and settled down in New York, subsequently holding exhibitions of personal works or joint exhibitions on modern fine arts in Chicago University, Manhattan’Soho, New York Rockefeller Center, and France, Japan, Hong Kong and Taiwan. In 1999 he returned to Shanghai to operate the Hard Han Cafe Theatre, and run Downstream Garage from 2004 to 2013.
} 
Fudan Poetry Club, wanted to express her intention of performing as "just want to express". ${ }^{4}$ Her script carries the imprint of poetic language inevitably. Reading it is enjoyable, but when it comes to performance, those scripts are abstruse and difficult to understand which set an artificial barrier for the audience to understand. Thus recklessly overturning of traditional theatrical conception, practices and conducts form the unique theatrical aesthetics of Uncertainty Theatre.

Uncertainty Theatre, which features its straightforward, extensive, simple and unsophisticated acting skills of amateur actors, and the postmodern narrative techniques such as dense collage and deconstruction, creates a theatrical presentation totally different from the linear narratives of traditional theatre. Three critical elements in traditional theatre, i.e., the dramatic dialogues, distinctive characters and intense plot, disappeared in the performance of Uncertainty Theatre. Actors with wooden or weird facial expressions, slogan like phrases or non-related dialogues often made the audiences confused. The first work of Uncertainty Theatre is called Three Drops of Water: Everyone Is Homosexual (2004), which is adapted from Gao Xiaoqin's novel. "Three drops of water" is the name of a drama bookstore in the novel and "homosexual" is a tag term without practical meaning, which is equivalent to "everyone is XXX". The whole play did not involve any homosexual topic. For this reason, some audiences who were attracted to the title felt quite disappointed after the end of the play.

Fairy, shepherd and modern life collided and co-existed on the stage, conveying the sharp criticism towards current social issues. Both the form and content in the post-modern style was not easy for audience to understand and accept. In 2005, Mary and Marlene, adapted from a work by Taiwan playwright Tian Qiyuan, focused on contemporary women's self-consciousness and began Gao Xiaoqin's non-narrative theatrical aesthetics. With the fragmented words and simple stage prop as one table and two chairs, two female roles, Mary and Marlene laughed, touched, moaned and wailed on stage, accompanied by their sharp criticism on politics, circumstances and desires. As the director, Gao Xiaoqin intended to explore the consciousness of women and transmit her questions and thoughts on social issues to the audiences.

II: Paper Door (2005) was another play of female issue, adapted from one of Gao Xiaoqin's poems. Unlike Mary and Marlene, it emphasized on the confusions of the adolescent girls. However, the conflicts between poetic narration and theatrical performance led to the leaping between theatrical presentation and incomplete narrative of the story, which split the audience into two radical ends: full of praise and refusal with confusion, thus forming the unique characteristics of Uncertainty Theatre, utilizing anti-grammar performances as its own theatrical grammar and deploying undetermined and flowing meaning to maintain its theatrical openness. In the following plays like Antigone (2005), Diary of Seduce(2007) and Floating Language series (2009, 2010), its uncertain style had been further strengthened. It preferred non-narrative style and pursued pure presence rather than imitated unpresent reality, meanwhile separating performance from the text, decomposing the lines, narrations, characters and other dramatic factors, by which constructed its own theatrical aesthetics.

Gao Xiaoqin knew that the performance of Uncertainty Theatre had never the effect of pleasing the audiences entirely. Bu what she pursued was "all unpredictable, quality thinking and practice" in a free theatrical space, and the release of body energy and its transformation in live performance. ${ }^{5}$ In 2009, Floating Language, the experimental series of Uncertainty Theatre, turned into the intellectual exploration of the

\footnotetext{
${ }^{4}$ Gao Xiaoqinis a drama director and poet, who graduated from Department of Chemistry, Fudan University in 1990. She published three volumes of poems like The Initial Scar Means the Final Recovery, I Am a Child and Who Feeds Me, Travel and so on.

${ }^{5}$ Gao Xiaoqin: Our Theatre, Journal of Shangha Culture, 2010 (5).
} 
language and revealed the poverty of words and real existence of the body in social reality. Floating Language I was the first work of Gao Xiaoqin's linguistic theatrical production, which employed fragmentary poetic languages and body gestures, as well as primitive voices such as mantras and meaningless "babbling", to explore the linguistic essence. In the play, the language and the body were two sides of a coin, where words of the role expressed senses and rhythms of the body. Meaningless primitive language or incantations seemed to be materialized to produce wonderful visual effects, and the concept that language should subordinate to drama was broken in the theatre. Just as Antonin Artaud talked about the pure materiality of language in The Theatre of Cruelty:

It flows into the sensibility. Abandoning Occidental usages of speech, it turns words into incantations. It extends the voice. It utilizes the vibrations and qualities of the voice. It wildly tramples rhythms underfoot. It pile-drives sounds. It seeks to exalt, to benumb, to charm, to arrest the sensibility. It liberates a new lyricism of gesturewhich, by its precipitation or its amplitude in the air, ends by surpassing the lyricism of words. It ultimately breaks away from the intellectual subjugation of the language, by conveying the sense of a new and deeper intellectualitywhich hides itself beneath the gestures and signs, raised to the dignity of particular exorcisms. ${ }^{6}$

This probably could be able to explain the revolutionary experiment on theatrical language conducted by Uncertainty Theatre, to explore the hidden sensibility and intelligence beneath the language. Not following the normal dramatic logic but with incomplete structure, non-linear narrative and fragmented images and scenes, Floating Language was not well understood by the audiences and joked as "uncertainty equals no understanding”. But for Gao Xiaoqin, "there is no infallible logic in this world.” The theatre was saturated with the fragmented words such as "collective consciousness", "collective unconsciousness", "time”, "seeking” and "horror", revealing the director's intention of connecting the individual and the world through theatrical practice. ${ }^{7}$

\section{Questioning Body Theatre: Grass Stage}

On the evening of December 4th, 2011, in the overcrowded Ke Center theatre, Fengzi ${ }^{8}$ wearily rushed about in a hurry in the theatre to search for a precious medicine which would increase the degree of leukaemia sufferers' blood coagulation. This story originated from his own personal experience. In the summer of 2010, Fengzi looked for medicine all day long for his father suffering from leukaemia. He encountered countless troubles and experienced the approach of death all the way. Before his father's death, Fengzi's daughter was born. Death and nativity, dolefulness and happiness simultaneously stepped into his 27-year-old's life. He incorporated this personal experience into the second section of The Little Society. When he was looking for medicine for his father he was also looking for medicine to cure the diseased society. "Do you have medicine?" asked the dispirited and cynical young man, who did not throw away any hope, and repeated this question to anybody he met. In the summer of 2009, in the first section of The Little Society performed in Downstream Garage, Fengzi moved the story between him and a prostitute into the theatre.

I have known her for many years, and it is odd that we have always kept a friendship. When we are watching society, sometimes we would feel that it is unfair, but what on earth is the relation between the society and us? What on earth is the

\footnotetext{
${ }^{6}$ [France] Antonin Artaud: The Theatre of Cruelty, translated by Gui Yufang, Beijing: China Theatre Publishing House, 2006, P. 80.

7 Site brochure of Autumn Harvest 2009.

8 The nickname Fengzi means madman in Chinese, his original name is Ge Weida, who graduated from Donghua University in 2005. In 2006, he joined in the Grass Stage, working as a core member until now.
} 
relation between her and me? How could I sympathize with her? I am sure we are discussing not only the simple relation between disparate people, but also the relation in terms of the social structure. I want to discuss this question with the people in the theatre, so that if this question is clarified, the issues 'concerning the bottom of society' may be understood more easily and smoothly. ${ }^{9}$

The Little Society series was put forward by Grass Stage respectively in 2009 and 2010. The consistent mode of the combination of collective creation and individual performance is adopted in these works, and the performers' meticulous observation of society is taken as the creative material for presenting bitterness and happiness of a variety of those at the bottom of society. Fengzi's performances mentioned above expound the connotation of "body theatre" advocated by Grass Stage to a certain extent: body is considered as the most essential and fundamental expressive means of theatre, stressing that "setting out from the body's nature to approach his own, personal and social community's truth."10

Zhao Chuan ${ }^{11}$, a writer, is one of the founder of Grass Stage. His transition from literary writing to theatrical practice started from a theatrical practice he participated in in 2004 in Korea."Sometimes literature really indulges in self-admiration, and only gets very indirect feedback, while theatre can produce an effect instantly with stronger social reactions.” Attending The $38^{\circ} \mathrm{N}$ Line Game performance in Kwangju, Korea made the writer "vaguely feel that the 'actors' on the stage and their performance skills imply the separation and phoniness of themselves in the monopolized system. Therefore I wanted to cooperate with more 'common' people on the stage. And then some interested people without any professional acting skills were gathered together to begin the earliest collective creation and self-training of Grass Stage." ${ }^{\prime 2}$ It was the theatre that enabled Zhao Chuan to have an access to publicity. To emancipate performance from the bondage of text and language and to center the body and its expressive force in the theatre is the foundation for Grass Stage to establish its theatrical aesthetics. At the beginning of 2005, Zhao Chuan and his friends initiated theatrical practice in Shanghai, taking” Grass Stage” as the name in order to stress the collective's property of grass roots and inspire the ordinary people to step into theater to express themselves independently. To a certain extent, the ordinary urban young people like Fengzi could obtain an opportunity for expressing themselves, find an approach to the publicity. Therefore, people who "have the desire to speak" from all walks of life gathered at "Grass Stage", among them being white-collars from companies, floating young workers, college students, housewives and unemployed young men.

During the transition from literary writing to theatrical articulation, body is the main articulative means for theatre. As Zhao Chuan put it in Body Theatre, it "implies the cause and effect in our life, represents a certain social order and claims, it does not make up stories with rhetoric, but instead it has its own legends."13 Among the theatrical works, $38^{\circ} \mathrm{N}$ Line Game took the form of a workshop and deployed various body languages to

\footnotetext{
${ }^{9}$ Interview with Feng Zi on December 30th, 2011 at Rose Garden beside Shanghai Theater Academy.

10 Zhao Chuan: Body Theater, Shucheng 2010 (7).

11 Zhao Chuan, born in 1960s, living abroad for years, now settles down in Shanghai. The scope of his creation covers literature, drama, movie, and visual arts. He was once the visiting scholar of Beijing University and writer stationed in Taipei. In 2001, he was awarded the first prize of Uinitas Award For New Novelists of Taiwan for his novel Mandarin Duck and Butterfly, and got Australian national fund on literature in 2000. His works includes Shanghai Abstract Story (art history), Not Abandon Home (prose), Mandarin Duck \& Butterfly (novel), The Overseas (prose),Eight Odds in Sydney (prose), Zhao Chuan's Photography Collection in Australia (photography), etc. In recent years, he works on and promotes development of non-profit populist theatre, planning series of performances and art exchanges both internally and externally, and activating the non-professional performers' theater energy.

12 Zhao Chuan: Body Theater, Shucheng Journal 2010 (7).

13 Zhao Chuan: Body Theater, Shucheng Journal 2010 (7).
} 
express people who had been separated but whose affection had never been separated over 50 years by means of metaphor or direct satire games. Later, the Taibei $38^{\circ} \mathrm{N}$ Line(2005)derived from this drama moved the context of the story into China. Madmen Story (2006) continued the mode of collective creation, with a psychotic's return to society after recovery from illness as a clue. In this play, much content derived from the social news and legal cases reported in the newspapers, "and presented the direct relationship between individuals, society and theatrical performance, and revealed the material desire and indulgence and psychological unbalance instigated by developing capitalism in contemporary China." ${ }^{\text {14 }}$

After Madmen Story, Zhao Chuan developed a new thought and collation on the positioning and development of Grass Stage as well as its theatrical aesthetics, and then put forward the concept of "questioning body theatre", to build an effective relationship between the "theatre" and the "social field". It means that the "theatre should use a certain method to approach its own, personal and social community's truth, and the process of questioning is just the theatre, which functions as a path to reflect on our life as well as various problems encountered in our life...it does not make up theatre, instead it urges the occurrence of theatre, thereby to construct a public sphere where expression could be made independently and confidently by ordinary people.” 15

In 2009 and 2010, Grass Stage put forward the first and second sections of the Little Society in succession, which adopted a method of collective creation and presenting individual pieces as a whole, the production drew on the performers' meticulous observations of society to represent the lives of the urban underclass. Obscure common people in everyday life became, on stage, the protagonists, the beggar, the prostitute, the rag-picker, the bootblack, the disabled veteran, the factory packer, the cashier in a supermarket, and the son looking everywhere for medicine to cure his father that was suffering from a fatal disease.

The Little Society series directed by Zhao Chuan followed his consistent theatrical posture of resistance, and the underclass ignored in our everyday life became the absolute leading roles on the stage: In Please Kneel Down, Ok?, Wu Meng and Chen Cheng sometimes knelt down and sometimes stood up under the orders shouted out by the administration personnel in the city, and they sometimes fought with each other to strive for an urban household while sometimes huddled in a paper carton and hugged each other to fall asleep. On the stage, sometimes they were honorable citizens, sometimes they were sorehead migrant workers, and their performance showed how a complete person under the administration of urban power's operation system was distorted and dissevered; In You and Me, Hou Qinghui respectively played the roles of a beggar and a nanny, crawling about producing terrified and desperate cries; Zhao Chuan wore a beam of light on his head and without stops or pauses took ten minutes to recite the draft and redefined "us". His speech poured out loudly, but every sentence touched the audience's heart (Our Name is...); Fengzi jumped in and out off the performance with his own body between a prostitute and himself as a performer (Story of Spring ); Fan Haoru played the role of his old uncle, who had always been a "revolutionary predecessor " but now was such an old and muddleheaded man, melting into a historical metaphor in his mumble and soliloquy, witnessing the great changes in his life and the tremendous vicissitudes of the country over 60 years...Grass Stage raised such problems with a posture of resistance: what kind of people live in the little society? What is their happiness, sadness or expectation? What makes them more open-hearted and dynamic? Who should perform their roles?

\footnotetext{
${ }^{14}$ Brochure of The Little Society section I.

15 Zhao Chuan: Memo of Grass Stage_zero six one zero, http://www.grassstage.com/main_r_zhaochuan_beian.htm
} 
These irrelevant independent stories were constructed into a frame by means of "compounding dispersed spots" to form the thickness or significance of life. In such an age which cannot be changed or where our ability to change is too tiny, this kind of artistic creation and its energy brought about by combinating individual and collective work could reveal the relationship between the society and individuals, leading the theatrical participants to awake or heal themselves.

The cultural strategy of Grass Stage was to strive for and create a fairer and open discussion space for common people with the grass-root's posture and a resistant spirit expressed by means of tactful theatrical language. They set out from the theatre, broke through the frame and boundary of the theatrical stage, and intervened in the realms of society, culture, politics and economics with their body performance, providing audiences with another form of subjective consciousness, broadening their vision and the various possibilities of stage representation. In such a cultural space, as Zhao Chuan put it,” it does not aim to meet the demand for the innovation of formalist art, instead it aims to perfect understanding of the relation between the theatre and social beings." ${ }^{\prime 6}$ The penetration of, intervention in and even questioning of social life helped build the publicity of Grass Stage theatre. Its sociality emphasizing a questioning-type theatrical ideology and non-profit-making attribute helps create the resisting consciousness by reflecting on the contradiction between the individual social beings and the state system .What's more, the subversiveness of the theatrical space to the urban capital/power presents the romantic ideals of the intellectuals with political diposition in the theatre who resisted capital and power through non-political theatrical approaches.

\section{Playwright Theatre: Linc2 Theatre Company}

Linc2 Theatre Company was founded in 2005 and was approved by the cultural authorities in Shanghai. It's a professional theatre troupe with performance license. Ren Mingyang, the founder and the key member of the troupe, tagged himself as "firstly as a playwright and then as a theatrical director" ${ }^{17}$ At the end of 2005, the first independent experimental theatrical production, Men in the Basement, Green Skirt Left (2005, scriptwriter: Li Xiaoliang, Ren Mingyang and Cai Yue, director:Ren Mingyang) was publicly performed successively in Downstream Garage, East China Normal University and Shanghai Theatre Academy. It was named by three scriptwriters playing "words combination game”, and was collaged by three different scripts created by the three scriptwriters separately. This method subverted the stereotypes of traditional theatrical production and inherent anticipation of audiences, thus causing extremely controversial critics.

After directing The Mass of Philosophy (2006,scriptwriter Yang Hongsheng and director Ren Mingyang) and Momo and Niannian (2006, scriptwriter Cai Yiyun and director Ren Mingyang), Shuangyong Road Last Night (2007, scriptwriter and director Ren Mingyang) was performed in public in 2007, and its intense experimental style sparked heated debate among the audiences. Shuangyong Road Last Night focused on the inner world of modern urbanites and explored the authentic beingin the consumerism era. The subsequent $L e$ You Yuan (2009, scriptwriter and director Ren Mingyang) continued the portrayal of modern lives in the urban cities. The non-logical narrative, incoherent plot and dismembered story were hard to understand and caused a lot of controversy. As for the working attitude, artistic ambition and the specific theatrical presentation, Shuangyong Road Last Night and Le You Yuan ,as well as Ren Mingyang’s other works, could be regarded as

\footnotetext{
16 Zhao Chuan: Memos of Grass Stage - zero six one zero, http://www.grassstage.com/main_r_zhaochuan_beian.htm.

17 Ren Mingyang, born in 1982, is a poet, playwright and theatrical director. He founded Linc2 Theatre Company in 2005, and then founded Ren Mingyang Drama Studio in 2009. The studio moved from Shanghai to Beijing in 2012.
} 
delicate, serious and sophisticated experimental performance in alternative theatres in Shanghai. The briefly designed and amply textured stage, live music and theme songs, were all originally devised especially for the play, as well as the finely designed video works, collections of poems and albums of pictures.

The theatrical productions of Linc2 Theatre Company focused on the theme of urbanites' identity-seeking and self-reflection on the contemporary life. In November 2009, This Time Next Year (2009, scriptwriter and director Ren Mingyang) premiered in the first Autumn Harvest Fringe Festivalin Downstream Garage. It continued the "seeking" theme, and four people performed on the stage and respectively uttered monologue to search for an absent character. Without a clear clue of the story, it was the first time Ren Mingyang ever created this form of performance. The stage was scattered with various props: washing machines, rice cookers, copy machines, high-power fans and scraps of paper which were blown in the air and then fell covering the whole stage. Despite the stage setting, music, lighting and sound design were totally creative, the noise setting in the scene transitions made many audiences unbearable. Similar with Ren Mingyang's previous works, This Time Next Year also brought forth extreme feedback from audiences.

In October 2010, Ren Mingyang’s Bon Bon Bon (2010) premiered in the second Autumn Harvest Fringe Festival in Downstream Garage. It's a story about a group discussion about what is good drama, occurring after the performance among four actors on a stage in chaos. It reflected Ren Mingyang's obsession and rethinking on the theatre and his observation on dominated consumption culture in the urban theatres. In the play, Xiao Yu (the role playing the actress of the troupe) stood in the middle of stage, i.e. the stage of Downstream Garage in reality, and performed a monologue. Her monologue repeated the question "what is this place”, which was also Ren Mingyang's introspection on theatre.

Since 2005, I have been experimenting and exploring the relationship with the audience. This play reflects my own thoughts of the theatre. Returning to the site, I've been thinking about questions like what this place is and why we are here, what the audiences are and what they're doing here, and should I please the audiences? ${ }^{18}$

Although almost every work had led to huge controversy, Ren Mingyang insisted on artistic taste that didn't cater to the audiences, which undoubtedly brought obstacles to receiving commercial benefits. The critics were constant and some people questioned its abstract and abstruseness "is this the director's fault or the audience’s fault?” Ren Mingyang responded, "the audiences prefer definite things, however, artists only raise questions instead of answering them. If you want realistic answers, go ask the politicians." ${ }^{19}$ Concerning his creation origin and the formation of theatrical aesthetic, he contributed them to his mission of returning to the theatre as a playwright. ${ }^{20}$

Ren Mingyang's theatrical productions were generally regarded as "the experimental theatres based on the innovation”. In his point of view, the “experiment” didn’t mean straying from the current society. Instead, it’s directly linked to the social reality and real presence and conducted the art experiments with Chinese characteristics, thus forming social influence to a certain extent. ${ }^{21}$

\footnotetext{
${ }_{18}^{18}$ Ren Mingyang answered the questions the audience asked after Bon Bon Bon performance on October 29, 2010.

19 Lu Yinyin: Linc2 Theatre Company Pulls the Intellectuals Back to Theatre, OPEN Fine Life Report, November 2009.

20 Ditto

21 After the "Momo and Niannian” premiere, Ren Mingyang replied online for the questions and controversy. See also http://blog.sina.com.cn/s/blog_5540382b010007ky.html.
} 


\section{Conclusion: Utopian Theatre and Subjectivity Reconstruction}

The efforts "to establish the connection between individuals and the world" of Uncertainty Theatre through the exploration of language, the social ideal of "endeavoring to build a questioning theatre to penetrate and get involved in the society" of Grass Stage, and the ontology probing of the experimental theatre ofLinc2 Theatre Company, all these demonstrate that the spiritual dilemma the urban intellectuals like Gao Xiaoqin, Ren Mingyang and Zhao Chuan are confronting is how to maintain their own continuity, integrity and consistency in the transitional period of society, and how to re-examine, redefine and re-identify themselves in contemporary society.

Gao Xiaoqin and Zhao Chuan's transition from writing to theatrical expression, and Ren Mingyang's self-identification of "firstly as a playwright and then as a director" demonstrate that the theatre has become a space for the social beings, especially the urban intellectuals to express themselves and respond to the rapid social changes.

The theatrical practices discussed above illuminate the social individual's initiatives when confronting the existential predicament in the consumption society. As a minjian theatre, Downstream Garage is not only a physical "site" or "venue", but also a cultural "utopia" with its definite connotation. The essence of theatrical production effected by urban intellectuals through the autonomous minjian theatres was to fully develop their critical spirit, to respond quickly to the changing society and to have a say in the social public field.

Under the impact of cosmopolitanism and nationalism in the 20th century, China's modern intellectuals played an important role in the process of Chinese revolution. In the 1930s, the League of Left-Wing writers participated as a significant force in promoting the modernization process of Shanghai by virtue of the literature and art movement. However, an important manifestation of the capitalization and mediocrity of cultural life is that intellectuals are becoming increasingly insignificant in the era of our lives, whose discourses have been weakened or even absent in the capital-dominated society. As the Italian Marxist Antonio Gramsci put, "all men are intellectuals, but not all men have in society the function of intellectuals."What he meant by that was that everyone has an intellect but not all are intellectuals by social function. In Said's view, the real intellectuals who are inspired by the metaphysical passion and the unbiased principles of justice and truth will denounce corruption, protect the weak and fight against the defective or oppressive authority. ${ }^{22}$ Based on theatres, the intellectuals in Shanghai switched themselves from writing to theatrical practice, trying to change, improve and revolutionize the world in which they live, highlighting the features of urban intellectuals in the 21st century.

Based on Downstream Garage, Shanghai minjian theatre troupes continued to improve, grow and mature through the theatrical practices. In the theatrical productions interpreting social reality from grassroots to the top, the cultural perspective of theatres aimed at social reality and produced a corresponding relationship with the extensive society, which demonstrated another possibility constructed in utopian theatre in daily life practice. Its anti-consumerism, breaking the production mechanism in theatres and advocacy and support for original creation led to a myth of anti-capital logic and realized cultural empowerment for social beings who had no choice in capital production system.

When the capitalized theatrical production becomes an industry, the theatre turns into a profit-seeking commodity and is deprived of its critical value, thus theatres become either the extensive force of political

22 [U.S] Edward. W. Said, Representations of the Intellectual, translated by Shan Dexing, Beijing: SDX Joint Publishing Company, 2007, p. 13. 
system or consumer goods of economic mechanisms, by which the capital-dominated theatrical aesthetics regulates the theatrical production. At the end of 2013, with the increasing financial pressure and without any economic benefits, Downstream Garage, being operated for a decade, was unable to survive and chose to shut down, which brought an end to the utopian theatre.

In the process of globalization, the development strategy of "international cultural metropolis" of Shanghai has further defined the cultural development orientation of the city. The theatrical practice in minjian theatres is responding to the expansion of financial capital and industrial productions in the urban cities. It shows that theatres have turned into an experimental venue for social individuals, typically the urban intellectuals, to resist consumer cultural hegemony and to conduct the social cultural changes. In the theatrical spaces they constructed respectively, performance is deployed to convey their thought and re-construct the subjectivity, which is the essence of artistic spirit of "minjian theatre".

\section{References}

Artaud, A. (2006). The theatre of cruelty (Y. F. GUI, Trans.). Beijing: China Theatre Publishing House.

Dolan, J. (2005). Utopia in performance. The University of Michigan Press.

Lefebvre, H. (2005). The production of space. Blackwell.

Said, E. W. (2007). Representations of the intellectual (D. X. SHAN, Trans.). Beijing: SDX Joint Publishing Company. 